\title{
Strengthening routine immunization in Papua New Guinea: a cross-sectional provincial assessment of front-line services
}

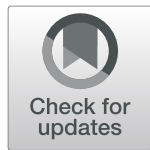

\author{
Christopher J. Morgan ${ }^{1,2^{*}}$ (D), Olga P. M. Saweri ${ }^{3} \mathbb{D}$, Nicholas Larme ${ }^{4}$, Elizabeth Peach ${ }^{1}$, Pele Melepia ${ }^{5}$, Lucy Au ${ }^{5}$, \\ Michelle J. L. Scoullar ${ }^{1,2} \mathbb{D}$, Mohammad Salim Reza ${ }^{6}$, Lisa M. Vallely ${ }^{3,7}$ (D), Barbara I. McPake ${ }^{8}$ id and James G. Beeson ${ }^{1,2,9}$ (D)
}

\begin{abstract}
Background: Routine immunization programs face many challenges in settings such as Papua New Guinea with dispersed rural populations, rugged geography and limited resources for transport and health. Low routine coverage contributes to disease outbreaks such as measles and the polio that re-appeared in 2018. We report on an in-depth local assessment that aimed to document immunization service provision so as to review a new national strategy, and consider how routine immunization could be better strengthened.

Methods: In East New Britain Province, over 2016 and 17, we carried out a cross-sectional assessment of 12 rural health facilities, staff and clients. The study was timed to follow implementation of a new national strategy for strengthening routine immunization. We used interview, structured observation, and records review, informed by theory-based evaluation, a World Health Organization quality checklist, and other health services research tools.

Results: We documented strengths and weaknesses across six categories of program performance relevant to national immunization strategy and global standards. We found an immunization service with an operational level of staff, equipment and procedures in place; but one that could reach only half to two thirds of its target population. Stronger routine services require improvement in: understanding of population catchments, tracking the unvaccinated, reach and efficiency of outreach visits, staff knowledge of vaccination at birth and beyond the first year of life, handling of multi-dose vials, and engagement of community members. Many local suggestions to enhance national plans, included more reliable on-demand services, integration of other family health services and increased involvement of men.

Conclusions: The national strategy addresses most local gaps, but implementation and resourcing requires greater commitment. Long-term strengthening requires a major increase in centrally-allocated resources, however there are immediate locally feasible steps within current resources that could boost coverage and quality of routine immunization especially through better population-based local planning, and stronger community engagement. Our results also suggest areas where vaccination campaigns in PNG can contribute to routine immunization services.
\end{abstract}

Keywords: Papua New Guinea, Low- and middle-income country, Routine immunization, Campaign, Vaccination, Measles, Polio, Health service delivery

\footnotetext{
* Correspondence: chris.morgan@burnet.edu.au

${ }^{1}$ Burnet Institute, Melbourne, Australia

${ }^{2}$ Melbourne School of Population and Global Health and Department of

Medicine, University of Melbourne, Melbourne, Australia

Full list of author information is available at the end of the article
}

(c) The Author(s). 2020 Open Access This article is distributed under the terms of the Creative Commons Attribution 4.0 International License (http://creativecommons.org/licenses/by/4.0/), which permits unrestricted use, distribution, and reproduction in any medium, provided you give appropriate credit to the original author(s) and the source, provide a link to the Creative Commons license, and indicate if changes were made. The Creative Commons Public Domain Dedication waiver (http://creativecommons.org/publicdomain/zero/1.0/) applies to the data made available in this article, unless otherwise stated. 


\section{Background}

Stronger routine immunization programs are critical to the ambitious Global Vaccine Action Plan (2011-2020), however immunization coverage is not increasing as planned in many difficult settings challenged by expanding childhood cohorts, population displacement by conflict or natural disasters, and limited resources to overcome geographical and infrastructural challenges $[1,2]$. With the outbreak of polio in 2018, Papua New Guinea (PNG)'s immunization program faces the question familiar to fragile systems enduring a crisis, that is: how in the wake of a major, rapid emergency response to plan for long-term strengthening of a program that has shown no increase in coverage over the past 15 years. The World Health Organization (WHO) and United Nations Children's Fund (UNICEF) estimated PNG's 2017 coverage at 62\% for both the third dose of diphtheria-tetanus-pertussis-containing vaccine (DTP3) and the first dose of measles-containing vaccine (MCV1), and at $60 \%$ for the third dose of oral polio vaccine [3], contrasting with Western Pacific Regional averages of 97\% [4] for these antigens.

Measles, having been suppressed by regular supplementary immunization activities (SIAs) for 8 years, returned to PNG in a major outbreak in 2014, and polio, after a 20 year hiatus, returned in 2018 [5, 6]. In that year, PNG was one of five countries experiencing outbreaks of circulating vaccine-derived poliovirus disease $[6,7]$, the rare mutated form that results from persistent low coverage with the oral polio vaccine. This has required one of PNG's largest public health emergency responses, led by the national government with support from Global Polio Eradication Initiative and other development partners [8]. In the short-term, the response entailed repeated SIAs, with longer term plans for program reform, recognizing that it is sustained gaps in routine immunization services that are the primary cause of this form of polio [7].

This paper reports on a cross-sectional health services assessment investigating PNG government efforts to improve routine immunization prior to the polio outbreak. PNG had in 2015 introduced a new strategy to improve routine immunization and reduce reliance on SIAs, termed the Special Integrated Routine EPI Strengthening Program (SIREP) $[9,10]$. This sought to improve program performance amidst the major challenges facing PNG's health services such as a stretched health workforce, financial constraints, and dispersed rural populations with minimal road access [11]. SIREP had four priorities: more efficient local planning based on locations of child populations, intensification of outreach services with realistic scheduling based on local resources, improved local information systems (including child health books), and staff training to support new vaccine introductions (most prominently Inactivated
Polio Vaccine (IPV) as well as pneumococcal and rubella vaccines). SIREP also aimed to integrate other primary health care with vaccination, starting with limited curative care, and addressing malnutrition through distribution of age-targeted vitamin A and anti-helminthic doses of albendazole [12]. SIREP attempted to merge the program intensification often seen in emergency campaigns [12] with internationally proven strategies for routine programming, such as those collated by WHO in "Reaching Every District (or Community)" [13] approaches and the Global Routine Immunization Strategies and Practices framework [14]. Our study aimed to investigate the relevance and effectiveness of SIREP in strengthening routine immunization through an assessment of front-line services. Such assessments are important to help guide the improvement of routine systems; an important longer-term complement to emergency responses such as those for polio.

\section{Methods \\ Study concept and objectives}

Our study focused on modifiable aspects of front-line services recognizing that, for coverage to increase, strategies to strengthen health system elements must ultimately enable changes in service delivery and uptake. Study objectives were to measure current infrastructure, equipment and supplies for preventive care in infancy; assess what health workers know, think and do in relation to providing postnatal and infancy services; assess health workers' responses to new strategies; and identify opportunities for health system strengthening and improved quality of care. We devised an evaluation framework that explicitly tested important elements of the SIREP strategy (noted in the Introduction), and that also referenced WHO standards for routine immunization programs $[14,15]$.

\section{Study setting and timing}

Our study setting was East New Britain province (ENBP), part of a large island in PNG's north-east, whose population (approximately 393,000) [16] live in small towns and rural villages in highland and coastal topographies. Immunization is usually provided through urban clinics, small rural health centres, scheduled outreach to community sites, and hospital children's outpatients. ENBP performs relatively better than other PNG provinces on some indicators (such as skilled attendance at childbirth), but immunization is similar to national estimates with $60 \%$ of children receiving DTP3 and $48 \%$ MCV1 in 2016 [17]. Our research was nested within a long-term multi-partner research initiative in ENBP termed Healthy Mothers Healthy Babies (HMHB) that examines broader issues of women's and children's health. 
We carried out a cross-sectional assessment of health facilities, staff and clients from November 2016 to January 2017, timed to follow the initial rounds of SIREP training and implementation. Sites surveyed comprised 12 clinics providing immunization services, nine in fixed facilities and three community outreach sites; purposefully chosen as they are all linked to the health institutions providing approximately $80 \%$ of maternal and child health care in ENBP [16]. Respondents for interview were chosen to provide a mix of seniority across frontline positions (Table 1).

\section{Data collection tools and ethical considerations}

Table 1 summarises the mix of interview, focus group discussion, structured observation and records audit. All tools reflected our evaluation framework by incorporating items testing core elements of the SIREP strategy, PNG's national immunization plans [11] and WHO standards for program monitoring [15], refined through consultation with national and provincial health managers. We also adapted WHO's 2015 Immunization Session Checklist [15] into a structured observation tool, devised a local tool to observe patient flow, and used concepts from realist evaluation to deepen interview questions with probes seeking respondents' views on context and mechanisms of change.

Data collection was carried out by trained local research officers using electronic tablets supplemented by paper-based note-taking. The research team included policy-makers and managers at national and provincial levels; however these investigators were excluded from front-line data collection or initial analyses, to avoid bias. Research officers were trained in quantitative and qualitative data collection, including techniques to minimise social acceptability bias, and to assess and counter perceived power imbalance between themselves and interview subjects. All free-text interview responses were recorded verbatim, focus group discussions were documented by a dedicated note taker, and both were digitally recorded for cross-checking. Interviews were conducted in English and focus group discussions in Tok Pisin; both official languages of PNG.

\section{Analysis}

Quantitative measures from audit, structured observation and interview elements (such as for knowledge) were reported as proportions with no further statistical manipulation, respecting the purposeful sampling in our design. Thematic analysis of qualitative data was carried out by the first author (after translation of focus group discussion data), then validated by three other investigators (including two Tok Pisin speakers). After coding for themes predetermined in our conceptual framework and design, data were re-examined for emergent themes. In 2017, for critique and validation, a detailed data report was provided to all investigators and a summary provided to national and provincial stakeholders; this also allowed early dissemination of policy implications. Additional file 1 is available detailing tables of all themes derived from interview and focus group discussions, and data structure for the observational tool.

\section{Results}

Key findings from all data sources are summarised under six categories (Table 2) from our evaluation framework that combined priorities addressed by the national SIREP strategy [5, 11], WHO program advice [15] and the results of our thematic analysis. We present quantitative and qualitative findings in combination, to show the overall finding against each element of the evaluation framework, in particular the degree to which SIREP objectives were seen in practice. Findings were additionally categorised as either local strengths or areas needing improvement, with decisions on this allocation being made by the research team. A comprehensive table of findings and themes is available as Additional file 1, Tables 1 and 2 .

\section{Local service planning, infrastructure, supplies and staffing}

Findings demonstrated that services were largely provided as planned from static clinics and some outreach

Table 1 Data collection, respondents and tools

\begin{tabular}{llll}
\hline Study subjects & Number & Details & Tools \\
\hline Primary health care staff & 6 & $\begin{array}{l}\text { Health Extension Officer or Specialised } \\
\text { Nursing Officer }\end{array}$ & Semi-structured interviews (mix of quantitative and qualitative fields) \\
& 6 & $\begin{array}{l}\text { Nursing officers } \\
\text { Community Health Worker (CHW) }\end{array}$ & \\
Family members & 67 & $\begin{array}{l}\text { Caregivers of infants being vaccinated, } \\
66 \text { female 1 male }\end{array}$ & Focus group discussion (10 groups) \\
$\begin{array}{llll}\text { Health clinics and their } \\
\text { operations }\end{array}$ & 9 & $\begin{array}{l}\text { Child or family health clinic, static } \\
\text { Mobile child health clinics (run by staff } \\
\text { from the above sites) }\end{array}$ & $\begin{array}{l}\text { Audit of infrastructure and equipment against PNG standards as } \\
\text { described in national EPI plan [1]. } \\
\text { Observation of general clinic procedures (12 sites) } \\
\text { Observation using WHO Immunization Session Checklist (11 sessions) } \\
\text { Observation of patient flow and staff-patient interactions (15 patients) }\end{array}$ \\
\hline
\end{tabular}


Table 2 Key findings, categorised by study themes, encompassing SIREP and WHO program improvement priorities

\begin{tabular}{ll}
\hline Local service planning and delivery & - Recent innovations recognised by most (14/ \\
Data sources: interview and audit & 18) staff: new vaccines or planning, with one \\
& mention of new quarterly outreach increasing \\
efficiency & \\
- Recent in-service training in SIREP reported by & many (11/18) staff \\
- Static services available 5 days per week \\
- All clinics tallied vaccinations to report into \\
national health information system \\
- $82 \%$ of clinics conducted as planned (annual \\
total of 109 implemented of 133 planned)
\end{tabular}

Opportunities for improvement in local systems

- Outreach was limited - minority (2/9) static

facilities used outreach with overnight stays

for remote areas

- Outreach planning process not able to be described by half the staff, less than a quarter planned on population basis, no clinics used population data to estimate outreach supply quantities

- Many clinics with few patients: mean 17/

clinic, IQR 3-26, maximum = 62

- Estimation of coverage impossible for more than half (10/18) staff due to lack of catchment data, only one clinic displayed coverage

- No clinics with lists of children overdue for vaccination, one third of clinics used child registers

- Local reasons for clinic cancellation were adverse weather, lack of transport or slow disbursement of funds

Infrastructure and supplies

Data sources: interview, audit and observation

Staff knowledge and staff practice during immunization sessions

Data sources: interview and observation

Missed opportunities for vaccination

Data sources: interview, audit and observation
- Most clinics had road access, with two outreach clinics on walking trails

- Water supply in nine (of 12) clinics and electricity in eight (of 9) static sites

- Functional injection equipment, safety boxes and weight scales in all clinics

- 10 (of 12) clinics with appropriate, functioning cold chain equipment

- Supplies of all relevant vaccines (including IPV and $\mathrm{PCV}$ ) and injection equipment present

- No expired or discontinued vaccines found

- More than half of staff could correctly cite recently introduced vaccines $(11 / 18)$ and handling of Iyophilised multi-dose vials (15/18)

- Twenty staff (nurses and CHWs) across 12 clinics, vaccinating mean of 17 children per clinic falls below WHO maximums (30 per staff member [15]);

- Core interactions (weight, screening and vaccination) done for 14 of 15 observed patients

- Observation against WHO session checklist (Fig. 1) shows key elements of safe injection in over $80 \%$ sessions

- Most staff (13/18) stated they would open a multi-dose vial for just one patient
- Eight (of 12) clinic sites needed renovation (by local standards), 9 (of 12) did not have usable toilets

- No clinics with kits for managing severe acute adverse events

- Cold storage monitoring inconsistent, no clinics with written temperature records - Half the clinics had clear records of vaccine stock usage, not well reconciled with tallies of patients vaccinated, none able to match supply to population

- Recording forms did not clearly account for three new vaccines: IPV, PCV, MR

- Lack of important guidance documents: one (of 12) had an immunization manual, and four had child health standard treatment guidelines

- Less than half of staff could correctly cite immunization schedule (8/18), one nationa program target (3/18), storage temperature $(6 / 18)$, interpret vaccine vial monitor display $(3 / 18)$, or handling of liquid multi-dose vials $(2 / 18)$

- Some important functions omitted in patient flow observations: educational interactions observed for just two of 15 patients, preventive care for mother and AEFI monitoring observed in none

- Waiting times in 15 patient flow observations were significant: mean $51 \mathrm{~min}$ arrival to final interaction (IQR 13-90, maximum 210)

- Observation against WHO session checklist sessions shows gaps in preparatory checking of vaccines, client communication and AEFI observation, and (for less than 20\%) in safe injection

- Due vaccinations had been missed in 3 of 10 Child Health Record books

- Reasons for missing vaccination included vaccine out of stock, clinic visit not for purpose of vaccination, or (for birth doses) childbirth in community

- Two (of 15) observed patients asked to return another day for vaccination

- Thirteen (of 17 respondents) staff stated they would usually ask a sick child to return at 
Table 2 Key findings, categorised by study themes, encompassing SIREP and WHO program improvement priorities (Continued)

\begin{tabular}{|c|c|c|}
\hline & Strengths in local systems & Opportunities for improvement in local systems \\
\hline & & another time for vaccination \\
\hline $\begin{array}{l}\text { Integration of other services } \\
\text { Data source: interview and } \\
\text { observation }\end{array}$ & $\begin{array}{l}\text { - All staff noted a policy of integrating other } \\
\text { care and vaccination } \\
\text { - Nine (of 18) staff cited at least one other care } \\
\text { (usually childhood illness) regularly integrated } \\
\text { - Child illness care available in nine (of 12) } \\
\text { clinics } \\
\text { - Child illness care accompanied vaccination in } \\
\text { seven (of 15) observed patients } \\
\text { - Weight measured in all observed patients }\end{array}$ & $\begin{array}{l}\text { - Four (of 18) staff mentioned maternal health } \\
\text { service as integration option } \\
\text { - Three clinics (of 12) lacked supplies, or } \\
\text { service organization, to integrate childhood } \\
\text { illness care with vaccination } \\
\text { - No observation of catch-up vaccination with } \\
\text { children presenting for illness } \\
\text { - Three (of 15) patients observed to receive } \\
\text { feeding counselling, two to receive vitamin } \\
\text { A, } 1 \text { to receive albendazole } \\
\text { - No observations of maternal preventive care } \\
\text { or counselling } \\
\text { - Staff reported insufficient numbers as main } \\
\text { constraint on integrated care }\end{array}$ \\
\hline $\begin{array}{l}\text { Community engagement and family viewpoints } \\
\text { Data sources: interview, observation and focus group } \\
\text { discussion }\end{array}$ & $\begin{array}{l}\text { - Three (of 12) clinics provided verbal group } \\
\text { health education alongside vaccination } \\
\text { sessions } \\
\text { - Three (of 18) staff reported support (for } \\
\text { example food) provided by local communities } \\
\text { - No fees for vaccines reported or observed and } \\
\text { families did not report fees as barrier to } \\
\text { vaccination }\end{array}$ & $\begin{array}{l}\text { - No reported use of community-based } \\
\text { trained lay health workers to help with } \\
\text { organization, mobilization or education. } \\
\text { - Six (of } 12 \text { ) clinics charged small } \\
\text { administrative fees } \\
\text { - Many families ( } 6 / 10 \text { groups) cited travel time, } \\
\text { and transport costs, as significant constraints } \\
\text { on timely attendance for vaccination } \\
\text { - Many families ( } 6 / 10 \text { groups) sought more } \\
\text { mobile clinics, more "on-demand" } \\
\text { vaccination, and more reliable clinic timing } \\
\text { - Some families ( } 4 / 10 \text { groups) sought more } \\
\text { respectful staff-client interactions } \\
\text { - No male family members were observed in } \\
\text { attendance, staff cited embarrassment as a } \\
\text { constraint on male involvement }\end{array}$ \\
\hline
\end{tabular}

Notes: SIREP Special Integrated Routine EPI Strengthening Program, IPV Inactivated polio virus vaccine, PCV Pneumococcal vaccine, MR Measles-rubella combination vaccine, IQR Interquartile range

sites (Table 2). Several key aspects of SIREP were not yet implemented; there was limited intensification of outreach, no selective targeting of population concentrations, and minimal systems for tracking and finding under-vaccinated children. Infrastructure and supplies review showed a functional level of infrastructure, equipment and supplies across almost all operating clinics, as judged against standards in the national EPI plan. New vaccines were being deployed in keeping with the SIREP strategy and, reassuringly, no expired or discontinued vaccines (such as trivalent oral polio vaccine) were found. However there were important unmet needs for renovation, equipment renewal, improved temperature monitoring, and availability of guidance documents. A significant gap was the absence of equipment to manage severe adverse events following immunization (AEFI). Overall staffing was within WHO global standards for workload (30 vaccinees per staff member [15]) at current levels of operation, noting a number of clinics with relatively few patients (25\% seeing three or fewer).

\section{Staff knowledge and service delivery practices}

Interviews (Table 2, with additional quantitative detail in the Additional file) showed some staff recognising SIREP objectives, many staff understanding the essentials of safe and effective vaccination, and all staff reporting recent refresher training. Important knowledge gaps related to vaccines given at birth or in the second year of life, the links between vaccination and disease control, and proper handling of liquid multi-dose vials (with the risk that usable vials would be unnecessarily discarded). Structured observations tracking staff-patient interactions for 15 patients and applying the WHO Immunization Session Checklist to 11 immunization sessions (Fig. 1) demonstrated that while most staff provided a clean and effective vaccination injection, there were gaps in provision of education, counselling of families, AEFI readiness, and the checking of vaccines for heat or freezing damage. Several missed opportunities for vaccination were noted, as listed in Table 2 .

Most staff at interview reported integration of other services with immunization (Table 2) as important, but observation found limited practice. Although national guidelines recommend integrated care for all infants [18], it was observed that: child illness care was provided alongside vaccination for approximately $50 \%$ of infants; while most infants were weighed, counseling on feeding or growth was uncommon; vitamin A and albendazole was distributed less often than scheduled; and no instances of integrating care for the mother were seen. 


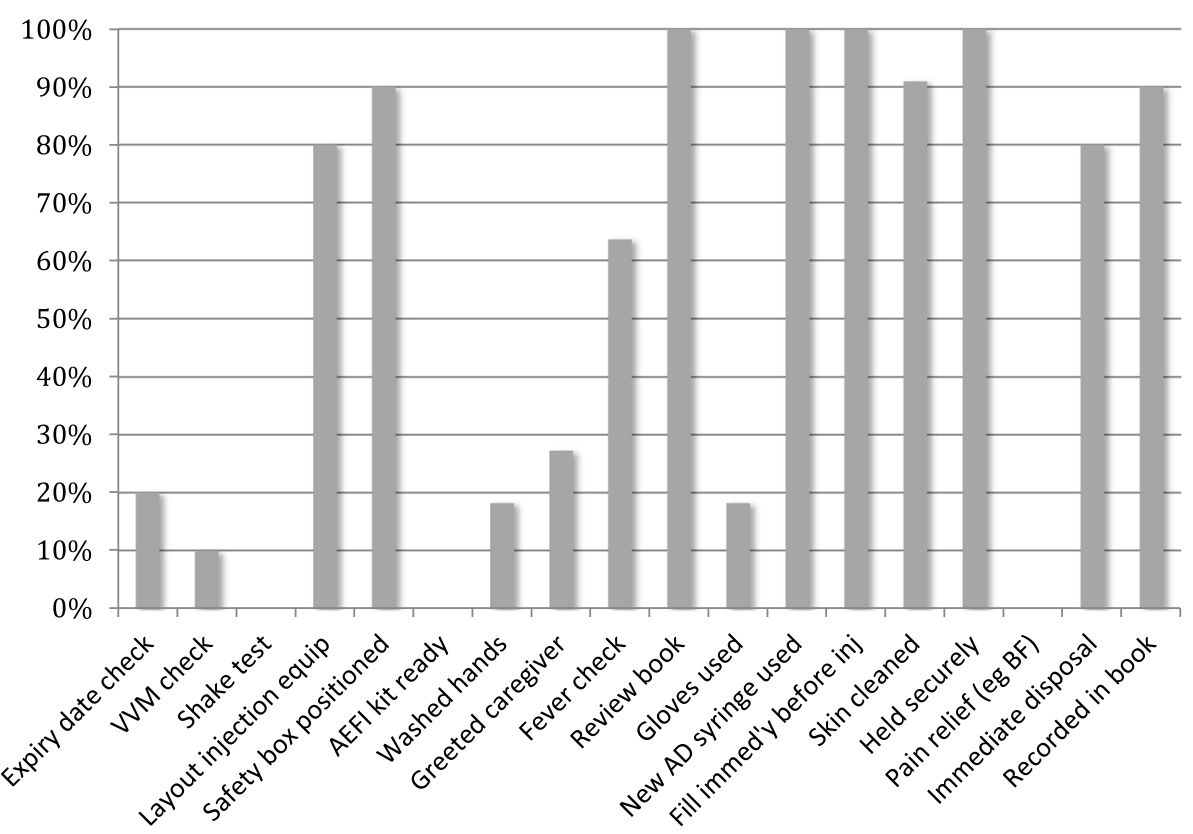

Fig. 1 Health worker practices assessed against the WHO Immunization Session Checklist (percentage of provider-client interactions showing the practice). Note: Structured observation of 11 immunization sessions, using the 2015 WHO Immunization Session Checklist [15], which aims to avoid the most common programmatic errors reported by senior immunization managers in a WHO consultation. WM= vaccine vial monitor, $\mathrm{AD}=$ Autodisable, $\mathrm{BF}=$ Breast-feeding

Staff reported lack of time and personnel as the most important constraints.

\section{Community engagement}

As listed in Table 2, community engagement activities consisted of group education talks at $25 \%$ of clinics, but without use of pictorial, video, participatory, or takehome communication products. Local communities donated in-kind support to some clinics, but there was no structured engagement, nor use of trained community health volunteers. Small fees (generally between USD 0.3-1.0) for attendance, but not for specific vaccines, were seen in one third of clinics, but were not reported as a major barrier to access. Male parents or care-givers were rarely involved in immunization visits. Community members reported lack of support from family members as an occasional barrier to vaccination.

\section{Locally generated ideas for improvement}

All participants (staff in interviews and community members in discussions), when prompted were able to describe local strengths or suggest improvements. Common ideas proposed by staff included more personnel, stronger support for transport needed to do outreach, better community engagement, more active community education, involvement of male parents or care-givers, and offering desirable extra services for both mother and baby. When asked to rank priorities, staff rated reliable vaccine supply and renewal of equipment and infrastructure as more important than staff numbers or staff knowledge. Care-givers sought more frequent, reliable and 'on-demand' services, especially outreach, noting travel time and costs as a common barrier to uptake. Mothers, more often than staff, asked for the addition of family planning, promotion of reproductive health, and maternal illness care at immunization clinics.

\section{Discussion}

Our findings depict an immunization service with an operational level of staff, equipment and procedures in place; but one that reaches just half to two thirds of its target population. The service strengths are similar to, or better than, many other sites in PNG [10], and the service deficiencies are similar to those identified for other low- or middle-income settings [1]. These findings point to a range of immediate opportunities to improve coverage and strengthen local service quality. We discuss these below and, in Table 3, synthesise them into ten recommended actions. By using an evaluation framework based on both PNG's SIREP strategy and WHO standards, it is possible to relate recommendations to what was included in PNG's SIREP strategy. Six of our ten proposed actions were already embedded in the SIREP strategy (and hence in national immunization plans), but insufficiently resourced or implemented in our study setting. Particular resource gaps lie in resourcing for outreach. Four actions proposed go beyond the current SIREP strategy. 
Table 3 Suggested local actions to improve routine immunization program coverage or quality, and potential contribution of emergency responses or campaigns, in rural Papua New Guinea

Local actions already proposed in the PNG government's SIREP strategy

Local planning based on populations rather than geography

Intensified quarterly outreach focused on higher clinic numbers properly resourced and implemented

System for tracking unvaccinated children

Integrated SIAs with additional vaccines, matching local priorities

Supportive supervision linked to refresher training including good communications and AEFIs

Trained lay health workers (health volunteers) to track births and children, support outreach clinics and promote uptake at static clinics

Local actions that go beyond the PNG government's SIREP strategy

Standardise every opportunity for vaccination, by policy, training and accessibility of vaccine supplies

Health communication products and programs to educate families on the complete vaccine schedule

Test models of integrated services, responsive to community preferences Review of staff roles and functions to optimise allocations and workload
Potential contribution of emergency responses or campaigns

Campaign coordinators help boost local routine planning capacity Mapping child populations and data-sharing

Identify new outreach points, especially with population clusters Clarify options and costs for transport

Mapping child populations and data-sharing

Involve district level in planning

Local flexibility in an expanded package of campaign services

Distribute resources to staff

Use campaign monitoring to collect staff priorities for capacity development

Campaign organisation that promotes local involvement Leverage campaign supports to enlist long-term interest and support

Potential contribution of emergency responses or campaigns

Not easily addressed by emergency responses or campaigns

Distribute family-oriented communications materials promoting catch-up vaccination

Not easily addressed by emergency responses or campaigns

Minimise incentives that discourage outreach as part of routine programs

Note: SIA Supplementary Immunization Activity. AEFI Adverse Event Following Immunization

\section{Options for short-term improvements in existing services}

Within current resources, improvements in coverage should be achievable with a fuller implementation of the changes to local service planning envisaged in the SIREP strategy. This recognises that many clinics see few clients ( $25 \%$ with 3 or less), and the fact that most planning is not yet tuned to where most children live. Other persisting gaps in knowledge and capacity that were prime targets of the SIREP strategy include improving catchment population data, increased frequency of service availability, a greater number of outreach points, and quarterly intensification of outreach. Change through improved local planning to reinvigorate outreach has proven successful in settings in Africa and Asia [13] that share similar burdens of disease and health system constraints to PNG. In past programmatic research in PNG, alongside the country's national coverage survey in 2004 [19] similar potential gains were identified. Reinforcement of SIREP training, already well recognised by front-line staff, appears a helpful starting point, but with a stronger commitment of resources to enable more outreach services. Such changes also meet many of the highest priorities expressed by family members in our study.

Our findings also indicate opportunities for increased community engagement and mobilisation; through increased group and individual counselling in the vaccination encounter and the creation and provision attractive, durable, "take-home" information products, aiming to build community demand for a timely, complete schedule of vaccination. Outreach can benefit from stronger, formalised involvement of local leadership, possibly with the deployment of trained lay health workers; such community resources can also help register and track children needing vaccination. Improved session practices, including ensuring managerial and stock support to enable staff to open multi-dose vials even for one child; and the institution of AEFI equipment and periods of observation (which also allows time for education). This mix of enhanced community engagement plus improved local planning has driven routine immunization improvements in difficult settings in sub-Saharan Africa [20, 21], and vaccination support by trained lay health workers, termed "Village Health Volunteers" in PNG, has been proven in this country in the past [22].

Interactions between campaigns and the routine program PNG's 2018 polio outbreak has necessitated a major emergency response, with national and sub-national campaigns initially for polio vaccination alone and later with other antigens, particularly measles-rubella, similar to previous SIAs in that country $[6,23]$. In Table 3 , we have suggested where, based on our findings, emergency responses or campaigns could synergise with the proposed actions to strengthen routine immunization. In other settings, the "micro-planning" used in polio and measles campaigns can inform local service planning [13]. Such planning was flagged in PNG's SIREP strategy 
but not fully implemented in our study site. Sharing of campaign coordination staff and systems to support local managers could help catalyse change by identifying new outreach sites, rebuilding local clinic registers and catchment descriptions, and setting benchmarks for sustainable, practical transport costs. Campaigns and emergency responses could also work for stronger community engagement, including communications with local leaders and trained health volunteers that advocate for long-term support to the continuing routine program. Other practical support could address the planning and information gaps noted in our study, by distributing Child Health Record Books, staff immunization manuals, and other key knowledge resources needed by the routine program.

There is global evidence, especially for measles/rubella SIAs, that they can boost routine programs [24]; but only if they accommodate the needs of routine immunization in the way they harmonise their planning, invest in suitably generic equipment, share staff and intelligence, use broadly supportive communications, and minimise unsustainable monetary incentives. PNG's past experience with SIAs suggest they had most success when they maximised district-level control of timing and operations, and of which package of services to integrate $[25,26]$.

\section{Longer-term issues}

It is clear that changes limited to the front-line are insufficient and central reforms of management, a countryled technical advisory group, procurement and financing, and national re-equipping are also needed and have been repeatedly advised $[10,11,27]$; these were largely beyond the scope of our research. Our findings do illuminate the need for new thinking on the immunization workforce; in interviews staff consistently mentioned lack of personnel as an important constraint on extending outreach or integrating new services, in contrast to our observations that staffing was more than adequate for the clinics actually operating. Expanding services will eventually require an expanded cadre of vaccinators, but prior to that our findings suggest a need to expand immunization responsibilities among existing staff, in pursuit of greater efficiency. This could be coupled with the reestablishment of commitment to the national immunization program goals across all staff levels, as one contribution to a revitalisation of immunization professionalism.

One aspiration of the SIREP strategy, and of global immunization programs [28], is the greater integration of other services with vaccination; seen to a limited degree in our study by the distribution of vitamin A or albendazole. Our community discussion findings reflect a demand for integration that goes beyond this, prioritising relatively complex services such as maternal illness care, or family planning counselling and provision.
These require time and skill that seem difficult within current staffing and infrastructure limits that we have mapped, and would seem to need an integration strategy such as service co-location rather than simply adding tasks to current vaccinators. Testing models to address maternal as well as infant needs through routine contacts in the first year after childbirth, appears profitable and important. If integrated service provision prioritises care that families want, this may help build demand for and confidence in immunization services, as well as meeting their felt needs.

\section{Limitations and strengths}

Our sample was restricted to functioning services and families who were willing and able to use those services so our study primarily relates to improving outcomes within existing services. Our data collection took place over the fourth and first quarters of the year, when wet weather events could bias perceptions of access. Despite careful training in unobtrusive observation and nonleading interviewing, there may be some observer effect and/or social acceptability bias affecting the validity of our findings. Single author coding of themes in qualitative analysis increases the risk of bias; our mitigation was to critically reflect on research perspective and carefully cross-check all inferences with local research staff, implementers and policy-makers. Study strengths include the assessment of a representative sample of functioning services, as well as the use of a broad mix of methods and attempt at more detailed interviewing than is the norm in previous service evaluations.

\section{Conclusions}

Our assessment of front-line immunization services in rural PNG found opportunities to boost coverage and quality, even within current resources, especially through better population-based local planning, and stronger community engagement. Many, but not all, were contained in PNG's recent national strategy (SIREP) for routine program strengthening. Our results call for increased resourcing of and commitment to this approach, and also suggest areas where vaccination campaigns in PNG can contribute to routine immunization services.

\section{Supplementary information}

Supplementary information accompanies this paper at https://doi.org/10. 1186/s12889-020-8172-4

Additional file 1. Additional quantitative knowledge data and thematic coding of qualitative data.

\section{Abbreviations}

AEFI: Adverse events following immunization; DTP3: Diphtheria-tetanuspertussis-containing vaccine third dose; ENBP: East New Britain Province; EPI: Expanded Programme on Immunization; HMHB: Healthy Mothers Healthy Babies research program; IPV: Inactivated polio vaccine; 
MCV: Measles-containing vaccine; PNG: Independent State of Papua New Guinea; SIA: Supplementary immunization activity; SIREP: Special Integrated Routine EPI Program; UNICEF: United Nations Children's Fund; USD: United States dollar; WHO: World Health Organization

\section{Acknowledgements}

All authors gratefully acknowledge: the families and health facility staff who participated in this study; PNG IMR leaders Professor Peter Siba and Professor William Pomat; Mr. Benedict Mode and the ENB Provincial Health Office; Mr. Moses Bogandri and Catholic Church Health Services; Dr. Beryl Vetuna, Regional Paediatrician, PNG Islands; Mr. Johnnie Arava, National Department of Health; Professor John Vince, University of PNG; Ms. Thalia Wat (national consultations), Mr. Wilson Philip (database management), Mr. Hadlee Supsup (coordination and logistics) and other staff of Burnet Institute in PNG; and the many private individuals in PNG and internationally that support the $\mathrm{HMHB}$ research program.

\section{Authors' contributions}

CJM conceived and designed the study, oversaw data collection, led analysis and interpretation, and led the preparation of the manuscript. JGB, MJLS and OPMS provided major contributions to study design. CJM, OPMS, EP, PM, and LA undertook data collection. OPMS, NL, EP, PM, LA, MJLS, MSR, LMV, BAMCP and JGB contributed to study design, analysis, interpretation, and the preparation of the manuscript. All authors reviewed and approved the final version of the manuscript.

\section{Funding}

Funding for study operations was provided by grants from the June Canavan Foundation Australia; Bank South Pacific Community Grant, Papua New Guinea; Finkel Foundation Australia; National Health and Medica Research Council of Australia (Research Fellowship to JGB [1077636], Postgraduate Scholarship to CM [1075065]). Burnet Institute acknowledges funding from the Victorian Operational Infrastructure Support Program, and the NHMRC Independent Research Institutes Support Scheme. Funders had no role in data collection, analysis, interpretation, manuscript preparation or decisions to publish.

\section{Availability of data and materials}

Summary tables of qualitative findings by thematic coding are provided available as supplementary material. Additional datasets used for the current study are available from the corresponding author on reasonable request.

\section{Ethics approval and consent to participate}

All participants provided written informed consent, with measures taken to ensure confidentiality. The study was approved by the PNG Institute of Medical Research Institutional Review Board (IRB: 1603), the PNG Medical Research Advisory Committee (MRAC: 16.22), the East New Britain Provincial Government (PEC: 12/2016), and The Alfred Hospital Ethics Committee, Melbourne (333/16).

\section{Consent for publication}

Not applicable.

\section{Competing interests}

One author (MSR) provided technical advice to SIREP as part of employment with WHO. Other authors declare no competing interests.

\section{Author details}

${ }^{1}$ Burnet Institute, Melbourne, Australia. ${ }^{2}$ Melbourne School of Population and Global Health and Department of Medicine, University of Melbourne, Melbourne, Australia. ${ }^{3}$ Papua New Guinea Institute of Medical Research,

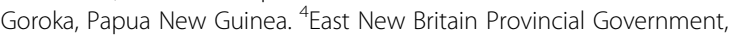
Kokopo, Papua New Guinea. ${ }^{5}$ Burnet Institute, Kokopo, Papua New Guinea. ${ }^{6}$ World Health Organization, Country Office Port Moresby, Port Moresby, Papua New Guinea. ${ }^{7}$ Kirby Institute, University of New South Wales, Sydney, Australia. ${ }^{8}$ Nossal Institute of Global Health, University of Melbourne, Melbourne, Australia. ${ }^{9}$ Central Clinical School and Department of Microbiology, Monash University, Melbourne, Australia.
Received: 2 June 2019 Accepted: 7 January 2020

Published online: 23 January 2020

\section{References}

1. Strategic Advisory Group of Experts on Immunization. 2018 assessment report of the global vaccine action plan. Geneva: World Health Organization; 2018.

2. Rainey JJ, Watkins M, Ryman TK, Sandhu P, Bo A, Banerjee K. Reasons related to non-vaccination and under-vaccination of children in low and middle income countries: findings from a systematic review of the published literature, 1999-2009. Vaccine. 2011;29(46):8215-21.

3. World Health Organization. World Health Organization and UNICEF National Immunization Coverage estimates Geneva. Papua New Guinea: WHO; 2018. [updated 4th July 2018; cited 2018 15th October 2018]; [National immunization coverage estimates global database]. Available from: http:// www.who.int/immunization/monitoring_surveillance/data/png.pdf.

4. VanderEnde K, Gacic-Dobo M, Diallo MS, Conklin LM, Wallace AS. Global routine vaccination coverage - 2017. MMWR Morb Mortal Wkly Rep. 2018; 67(45):1261-4.

5. World Health Organization. WHO vaccine-preventable diseases: monitoring system. 2018 global summary Geneva: World Health Organization; 2018 [updated 21st September 2018; cited 2018 15th October 2018]; Global database of vaccine preventable diseases]. Available from: http://apps.who. int/immunization_monitoring/globalsummary/countries

6. National Department of Health. Polio Outbreak Response, First 100 Days. Port Moresby: NDOH, Global Polio Eradication Initiative, UNICEF, World Health Organization; 2018.

7. Global Polio Eradication Initiative. Circulating vaccine-derived poliovirus. Geneva: World Health Organization; 2018. [updated 18th December 201810th January 2018]; Available from: http://polioeradication.org/poliotoday/polio-now/this-week/circulating-vaccine-derived-poliovirus/

8. World Health Organization Western Pacific Regional Office. Polio outbreak in Papua New Guinea Manila: World Health Organization; 2019 [updated 15th January 2019; cited 2019 20th January, 2019]; Available from: https://www. who.int/westernpacific/emergencies/papua-new-guinea-poliovirus-outbreak

9. World Health Organization. Papua New Guinea launches SIREP Plus. Global Immunization News. Geneva: World Health Organization; 2015.

10. Gavi Alliance. Joint Appraisal Report 2016. Gavi with National Department of Health, WHO Country Office, UNICEF Country Office; 2016.

11. National Department of Health. Comprehensive EPI Multi-Year Plan for National Immunization Programme 2016-2020. Port Moresby: NDOH; 2016

12. National Department of Health. Special Integrated Routine EPI Strengthen Program n Papua New Guinea (SIREP and SIREP Plus). Port Moresby: National Department of Health; 2015.

13. Vandelaer J, Bilous J, Nshimirimana D. Reaching Every District (RED) approach: a way to improve immunization performance. Bull World Health Organ. 2008;86(3):A-B.

14. World Health Organization. Global routine immunization strategies and practices (GRISP): a companion document to the global vaccine action plan (GVAP). Geneva: WHO; 2016.

15. World Health Organization. Immunization in practice: a practical guide for health staff. 2015 Update ed. Geneva: Expanded Programme on Immunization, World Health Organization; 2015.

16. National Department of Health. Provincial and district health profiles of Papua New Guinea. Port Moresby: Monitoring and Research Branch of NDOH; 2018.

17. Monitoring and Research Branch. Assessment of Sector Performance 20122016, National Report. Port Moresby: National Department of Health; 2017.

18. National Department of Health, editor. Standard Treatment Manual for Common Illnesses in Children. 10th ed. Port Moresby: National Department of Health; 2016

19. Clements CJ, Morgan C, Posanai E, Polume H, Sakamoto C. A qualitative evaluation of the immunization program in Papua New Guinea. P N G Med J. 2006:49(1-2):5-13

20. LaFond A, Kanagat N, Steinglass R, Fields R, Sequeira J, Mookherji S. Drivers of routine immunization coverage improvement in Africa: findings from district-level case studies. Health Policy Plan. 2015;30(3):298-308.

21. Favin M, Steinglass R, Fields R, Banerjee $K$, Sawhney M. Why children are not vaccinated: a review of the grey literature. Int Health. 2012:4(4):229-38.

22. Morgan C, Bisibisera L, Bauze A, Winjong H, Coppola A, Lagani W. Integrating birth-dose vaccination with early postnatal care in a remote setting in Papua New Guinea. J Paediatr Child Health. 2011;47:10. 
23. Taukari R. Papua New Guinea: over 1 million children to be vaccinated against measles-rubella and polio. Port Moresby: World Health Organization, Papua New Guinea Country Office; 2019.

24. Griffiths UK, Mounier-Jack S, Oliveira-Cruz V, Balabanova D, Hanvoravongcha P, Ongolo P. How can measles eradication strengthen health care systems? J Infect Dis. 2011;204(SUPPL. 1):S78-81.

25. Morgan C, Hinton R, Pongua G, Aeno H, Auwun A, Clements C. Better use of public health campaigns for child survival: the impact and operations of Papua New Guinea's supplementary immunisation activity 2003-05. Research Monograph, Child Health and Nutrition Research Initiative 2009.

26. Vince JD, Datta SS, Toikilik S, Lagani W. Integrated package approach in delivering interventions during immunisation campaigns in a complex environment in Papua New Guinea: a case study. Vaccine. 2014;32(36):4614-9.

27. World Health Organization, UNICEF Papua New Guinea, Centers for Disease Control, GAVI Alliance, Foundation OSH. International Review of the Expanded Programme on Immunization in Papua New Guinea. Port Moresby: National Department of Health Papua New Guinea; 2013.

28. World Health Organization. Working together: an integration resource guide for immunization services throughout the life course. Geneva: World Health Organization; 2018.

\section{Publisher's Note}

Springer Nature remains neutral with regard to jurisdictional claims in published maps and institutional affiliations.

Ready to submit your research? Choose BMC and benefit from:

- fast, convenient online submission

- thorough peer review by experienced researchers in your field

- rapid publication on acceptance

- support for research data, including large and complex data types

- gold Open Access which fosters wider collaboration and increased citations

- maximum visibility for your research: over $100 \mathrm{M}$ website views per year

At BMC, research is always in progress.

Learn more biomedcentral.com/submissions 